\title{
Characteristics of doxorubicin-selected multidrug-resistant human leukemia HL-60 cells with tolerance to arsenic trioxide and contribution of leukemia stem cells
}

\author{
JING CHEN, HULAI WEI, JIE CHENG, BEI XIE, BEI WANG, JUAN YI, BAOYING TIAN, \\ ZHUAN LIU, FEIFEI WANG and ZHEWEN ZHANG \\ Key Laboratory of Preclinical Study for New Drugs of Gansu Province, School of Basic Medical Sciences, \\ Lanzhou University, Lanzhou, Gansu 730000, P.R. China
}

Received December 29, 2015; Accepted June 9, 2017

DOI: $10.3892 / \mathrm{ol} .2017 .7353$

\begin{abstract}
The present study selected and characterized a multidrug-resistant HL-60 human acute promyelocytic leukemia cell line, HL-60/RS, by exposure to stepwise incremental doses of doxorubicin. The drug-resistant HL-60/RS cells exhibited 85.68-fold resistance to doxorubicin and were cross-resistant to other chemotherapeutics, including cisplatin, daunorubicin, cytarabine, vincristine and etoposide. The cells over-expressed the transporters P-glycoprotein, multidrug-resistance-related protein 1 and breast-cancer-resistance protein, encoded by the adenosine triphosphate-binding cassette $(A B C) B 1, A B C C 1$ and $A B C G 2$ genes, respectively. Unlike other recognized chemoresistant leukemia cell lines, HL-60/RS cells were also strongly cross-resistant to arsenic trioxide. The proportion of leukemia stem cells (LSCs) increased synchronously with increased of drug resistance in the doxorubicin-induced HL-60 cell population. The present study confirmed that doxorubicin-induced HL-60 cells exhibited multidrug-resistance and high arsenic-trioxide resistance. Drug-resistance in these cells may be due to surviving chemoresistant LSCs in the HL-60 population, which have been subjected to long and consecutive selection by doxorubicin.
\end{abstract}

\section{Introduction}

Chemotherapy serves an important and indispensable role in leukemia therapy. However, chemotherapy-induced multidrug

Correspondence to: Professor Hulai Wei, Key Laboratory of Preclinical Study for New Drugs of Gansu Province, School of Basic Medical Sciences, Lanzhou University, 199 Donggang West Road, Lanzhou, Gansu 730000, P.R. China

E-mail: weihulai@1zu.edu.cn

Key words: multidrug resistance, arsenic trioxide, leukemia stem cell, acute promyelocytic leukemia, HL-60 cells resistance (MDR) frequently induces therapy failure or tumor recurrence (1-3). MDR involves various mechanisms including, adenosine triphosphate-binding cassette (ABC) transporters, P-glycoprotein (P-gp), multidrug-resistance-related protein (MRP) and breast-cancer-resistance protein (BCRP) overexpression, which function to efflux certain molecules out of the cells (4-8). In addition, mechanisms of acquired MDR in leukemia also include abnormal drug metabolism and the presence of leukemia stem cells (LSC). LSCs are particularly of interest and considered to serve an important role in leukemia resistance and relapse (4). Numerous previous studies have confirmed that the rare LSC sub-population in leukemia has self-renewal abilities, uncommitted proliferative capacities, relative dormancy or quiescence, high expression of ABC transporters and good DNA-damage repair ability (9-12). In addition, LSCs have strong resistance to almost all chemotherapeutics $(2,5)$. However, the role of LSCs and the mechanism underlying transmission of super-drug resistance to daughter cells remains unclear. Additionally, the specific markers of LSCs remain uncertain. Previous studies have demonstrated that LSC populations are heterogeneous and may be defined as cluster of differentiation (CD) $34^{+}$, CD38-, human leukocyte antigen D related, CD90', CD117 ${ }^{-}$and $\mathrm{CD} 123^{+}$phenotypes $(3,13-17)$. Previous studies demonstrated that CD123 was aberrantly expressed on acute myeloid leukemia CD34+CD38- cells but was not detected on healthy $\mathrm{CD} 34^{+} \mathrm{CD} 38^{-}$cells. Therefore, the level of CD123 expression appears to be leukemic-specific and may be a criterion for identifying LSCs from abnormal hematopoietic stem cells $(13,14)$.

Previous studies have revealed that the majority of MDR leukemia cells have increased sensitivity to $\mathrm{As}_{2} \mathrm{O}_{3}$, rather than cross-resistance $(3,4)$. One potential explanation for this is that $\mathrm{As}_{2} \mathrm{O}_{3}$ may not be a substrate of $\mathrm{P}-\mathrm{gp}$ and may inhibit P-gp activity $(2,18-22)$. The present study selected HL-60 human promyelocyte leukemia cells for doxorubicin (ADM)-resistance by long-term exposure to intermittent and continuous stepwise increments of ADM, and characterized the distinguishing features of acquired MDR, particularly in terms of sensitivity to $\mathrm{As}_{2} \mathrm{O}_{3}$ and the role of LSCs. 


\section{Materials and methods}

Materials. $A B C B 1, A B C C 1, A B C G 2$ and $\beta$-actin primers were synthesized by Takara Bio, Inc. (Otsu, Japan). SYBR Premix Ex Taq and Prime Script RT reagents were obtained from Takara Bio, Inc. The following antibodies were used: Mouse anti- $\beta$-actin antibody (cat no. 3598-100; dilution, 1:1,000; BioVision, Inc., Milpitas, CA, USA), rabbit anti-P-gp antibody (cat. no. BA1351-2; dilution, 1:500), anti-BCRP antibody (cat. no. BA2307-2; dilution, 1:500), and anti-MRP1 antibody (cat. no. BA0567; dilution, 1:500) from Boster Biological Technology, Wuhai, China, PE-IgG1 (cat. no. GM4993), ECD-IgG1 (cat. no. A99022), PEcy5-IgG1 (cat. no. 85-15-4714-71), PEcy5-CD34 (cat. no. CD3458118) and ECD-CD38 (cat. no. 14-0389-82) and PE-CD123 (cat. no. 12-1239), FITC-BCRP (cat. no. lv1506735) antibodies (eBioscience; Thermo Fisher Scientific, Inc., Waltham, MA, USA), P-gp (MRK16; cat. no. Mc-012; Kamiya Biomedical Co., Tukwila, WA, USA). The chemotherapeutic drugs used were ADM (Shenzhen Wanle Pharmaceutical Co., Ltd., Shenzhen, China), daunorubicin (Zhejiang Haizheng Pharmaceutical Co., Ltd, Zhejiang, China), cisplatin and etoposide (Qilu Pharmaceutical Co., Ltd., Jinan, China), 5-fluorouracil (Haipu Pharmaceutical Co. Ltd., Shanghai, China), vincristine hydrochloride (Guangdong Lingnan Pharmaceutical Co., Ltd. Guangzhou, China), cytarabine (Haipu Pharmaceutical Co., Ltd.) and $\mathrm{As}_{2} \mathrm{O}_{3}$ (Sigma-Aldrich; Merck KGaA, Darmstadt, Germany).

Transmission electron microscope observation of cell ultrastructure change. Cells were harvested and washed with $0.1 \mathrm{M}$ PBS. The Cell pellets were immersed in $2.5 \%$ glutaraldehyde and incubated at $4^{\circ} \mathrm{C}$ for $48 \mathrm{~h}$. Following cell fixation, the sample was treated with $1 \%$ osmium tetroxide at room temperature for $1 \mathrm{~h}$ and then dehydrated in acetone for $30 \mathrm{~min}$. The sample was then embedded in embedding resin, followed by cutting into ultrathin sections with a microtome and lead-uranium double staining and then observed and photographed under a transmission electron microscope.

Scanning electron microscopy analysis. A total of $1 \times 10^{6}$ cells were washed with PBS and quickly fixed in precooled $2.5 \%$ glutaraldehyde (Sigma-Aldrich; Merck KGaA) at $4^{\circ} \mathrm{C}$ overnight. Following three washes in $0.1 \mathrm{M}$ PBS, the cells were fixed with ice-cold $1 \%$ osmium tetroxide (Sinopharm Chemical Reagent Co., Ltd., Shanghai, China) for 1.5-2 h, followed by sequential $15 \mathrm{~min}$ incubations in 50,70 and 80\% ethanol at $4^{\circ} \mathrm{C}$. Subsequently, fixing steps in 90 and $100 \%$ ethanol at room temperature, and gradually permeabilizing steps in a series of buffers that consisted of dehydrating agent acetone/isoamyl acetate (1:1) mixed with epoxy resin at a ratio of 2:1, 1:1 and $1: 3$, followed by $100 \%$ resin, for $0.5-1 \mathrm{~h}$ each incubation. Finally, the cells were soaked in tert-butyl alcohol twice for 10 min each time, dried with a vacuum pump for $24 \mathrm{~h}$ and platinum sputter-coated for $90 \mathrm{sec}$. The prepared specimen was observed under a scanning electron microscope.

Cell culture and incubation. HL-60 human promyelocyte leukemia cells were purchased from American Type Culture Collection (Manassas, VA, USA). The cells were maintained in RPMI-1640 (Gibco; Thermo Fisher Scientific, Inc.) supplemented with $10 \%$ fetal bovine serum (Hyclone; GE Healthcare Life Sciences, Logan, UT, USA) and cultivated at $37^{\circ} \mathrm{C}$ in a $5 \% \mathrm{CO}_{2}$ incubator.

Selection of ADM-resistant cells. HL-60 human leukemia cells were selected for ADM-resistance by long-term exposure to intermittent, repeated and continuous stepwise increments of ADM concentrations from $0.01-40 \mathrm{mg} / \mathrm{l}$. If the cells survived a given ADM concentration and proliferated at a similar rate to parental HL-60 cells, the concentration of treatment was increased. The procedure was repeated intermittently and repeatedly until the cells were stably able to tolerate $40 \mathrm{mg} / \mathrm{l} \mathrm{ADM}$. This procedure was used to generate a stable drug-resistant leukemia subline, named HL-60/RS.

In vitro drug sensitivity analysis. HL-60 cells tolerant to various concentrations of ADM were collected for determination of the half-maximal inhibitory concentrations $\left(\mathrm{IC}_{50}\right)$ of $\mathrm{ADM}$ and for cytotoxicity assays. A total of $1 \times 10^{5}$ cells $/ \mathrm{ml}$ were plated in 96-well plates and cultured at $37^{\circ} \mathrm{C}$ with corresponding concentrations of the aforementioned chemotherapeutics (ADM 1,2, 4, 6, 8, $10 \mathrm{mg} / 1$, cisplatin $1,5,10,20,40 \mathrm{mg} / 1$, etoposide $0.5,1$, $2,4,8,10 \mathrm{mg} / 1,5$-fluorouracil $0.5,1,2,4,8,16 \mathrm{mg} / \mathrm{l}$, vincristine hydrochloride $0.5,1,2,4,8,10 \mathrm{mg} / \mathrm{l}$ and cytarabine 0.5 , $1,2,4,8,10 \mathrm{mg} / \mathrm{l}$, all dissolved with $0.9 \%$ saline solution and $\mathrm{As}_{2} \mathrm{O}_{3}$, dissolved in sodium hydroxide as a storage concentration of $10 \mathrm{mmol} / \mathrm{l}$ whose $\mathrm{pH}$ value was adjusted with $1 \mathrm{~mol} / \mathrm{l}$ HCL to 7.2-7.4 and diluted to 2 and $5 \mu \mathrm{mol} / 1$ before using) for 24-72 h. Absorbance was quantified using a Powerwave $\mathrm{X}$ plate reader (Omega Bio-Tek, Inc., Norcross, GA, USA) by MTT assay. A total of $5 \mathrm{mg} / \mathrm{ml}$ MTT was added to each well and incubated at $37^{\circ} \mathrm{C}$ for $4 \mathrm{~h}$, then $100 \mu \mathrm{l} 10 \%$ SDS was added to each well and incubated at $37^{\circ} \mathrm{C}$ overnight; absorbance was then detected at $570 \mathrm{~nm}$ wavelength.

Reverse transcription-quantitative polymerase chain reaction $(R T-q P C R)$. Total cellular RNA was extracted using a TRIzol ${ }^{\circledR}$ kit (Invitrogen; Thermo Fisher Scientific, Inc.). cDNA was derived from the RNA as PCR template using the Prime Script reverse transcriptase kit (Takara Bio, Inc.). Temperature protocol: $70^{\circ} \mathrm{C}$ for $30 \mathrm{~min}, 37^{\circ} \mathrm{C}$ for $15 \mathrm{~min}, 95^{\circ} \mathrm{C}$ for $5 \mathrm{~min}$. For PCR, cDNA $(2 \mu 1)$ was mixed with SYBR Premix Ex Taq (Takara Bio, Inc.) and the following relevant primers for PCR were used: $\beta$-actin forward, 5'-TGCTCCTCCTGAGCGCAA GTA-3' and reverse, 5'-CCACATCTGCTGGAAGGTGGA-3'; $P$ - $g p$ forward, 5'CCCATCATTGCAATAGCAGG3' and reverse, 5'GTTCAAACTTCTGCTCCTGA3'; MRP1 forward, 5'TGCAGAAGGCGGGGAGAACCTC3' and reverse, 5'GTC GTCCGTTTCCAGGTCCACG3'; BCRP2 forward, 5'GCT GCAAGGAAAGATCCAAGT3' and reverse, 5'TAGTTG TTGCAAGCCGAAGAG3', which were designed and synthesized by Takara Bio, Inc. The conditions included an initial denaturing step at $95^{\circ} \mathrm{C}$ for $10 \mathrm{sec}$, then 40 cycles of denaturing at $95^{\circ} \mathrm{C}$ for $5 \mathrm{sec}$ and annealing at $60^{\circ} \mathrm{C}$ for $30 \mathrm{sec}$. The relative expression of each mRNA was calculated by comparison to $\beta$-actin mRNA using the $2^{-\Delta \Delta \mathrm{Cq}}$ method (4).

Western blot analysis. The cells were lysed using a radioimmunoprecipitation assay (RIPA) protein extraction reagent (cat no. P0013B; Beyotime Institute of Biotechnology, 

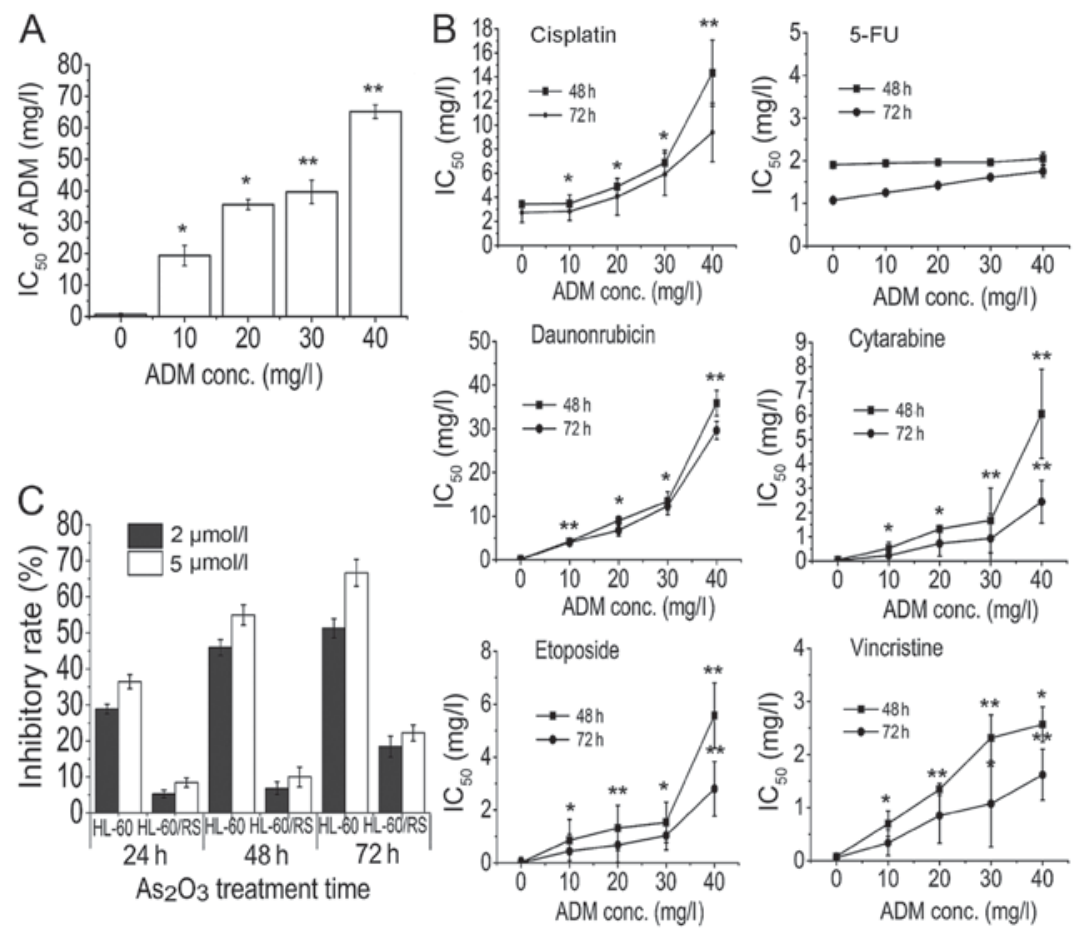

Figure 1. HL-60 cells acquire multidrug resistance. HL-60 cells resistant to 10-40 mg/l ADM were treated with various chemotherapeutic drugs. Inhibitory rate and $\mathrm{IC}_{50}$ values were determined by MTT assay. HL-60 cells resistant to $40 \mathrm{mg} / 1$ ADM were defined as HL-60/RS cells. (A) HL-60 cells became increasingly resistant to ADM at increasing concentrations of ADM and increasing exposure times. (B) ADM-resistant HL-60 cells were cross-resistant to other chemotherapeutic drugs, including cisplatin, daunorubicin, cytarabine, vincristine and etoposide, but not 5-fluorouracil. (C) HL-60/RS cells acquired high $\mathrm{As}_{2} \mathrm{O}_{3}$ resistance. ${ }^{*} \mathrm{P}<0.05,{ }^{* *} \mathrm{P}<0.01$ compared with $\mathrm{HL}-60$ cells. $\mathrm{IC}_{50}$, half-maximal inhibitory concentration; ADM, doxorubicin; conc., concentration; 5-FU, 5-fluorouracil.

Haimen, China), supplemented with phenylmethylsulfonyl fluoride (PMSF) $(0.1 \mathrm{mmol} / \mathrm{ml}$ PMSF $10 \mu 1$ in $1 \mathrm{ml}$ RIPA). Total protein concentration was determined using a BCA protein quantitative kit (cat no. P0010s; Beyotime Institute of Biotechnology). Proteins (30 $\mu \mathrm{g}$ per lane) were separated by $10 \%$ SDS-PAGE, transferred to a polyvinylidene fluoride membrane and blocked with 5\% skimmed milk at room temperature for $1 \mathrm{~h}$. Membranes were washed with PBS-Tween-20 (PBST) three times for $5 \mathrm{~min}$. The membranes were probed with primary antibodies (anti-P-gp, anti-MRP1 or anti-BCRP, with the same conditions as above) at $4^{\circ} \mathrm{C}$ overnight. The membrane was washed with PBST three times for 5 min. IRDye 800CW-(goat anti-mouse; cat. no. 926-32210; dilution, 1:10,000; LI-COR Biosciences, Lincoln, NE, USA) or IRDye680DX-conjugated secondary antibodies (goat anti-rabbit; cat. no. 926-32221; dilution, 1:10,000; LI-COR Biosciences, Lincoln, NE, USA) was added to the membrane and agitated for $1 \mathrm{~h}$ at room temperature prior to washing three times with PBST for 5 min, using the anti- $\beta$-actin antibody as the control. The blots of antibody-coated protein bands in immunoblots were quantitated and visualized using an Odyssey double-color infrared-laser imaging system (Odyssey v1.2 software; LI-COR Biosciences Inc., Lincoln, NE, USA).

ADM accumulation/efflux assay. In order to determine the intracellular uptake of ADM, the sensitive and resistant HL-60 cells were incubated with $30 \mathrm{mg} / \mathrm{l} \mathrm{ADM}$ at $37^{\circ} \mathrm{C}$ for $30 \mathrm{~min}$. Following two washes with PBS and re-suspension in $200 \mu \mathrm{l}$ PBS, intracellular uptake of ADM in $10^{6}$ cells was determined immediately using a MoFlo XDP Cell Sorter (Beckman
Coulter, Inc., Brea, CA, USA) with excitation at $488 \mathrm{~nm}$ and emission at $525 \mathrm{~nm}$ wavelengths. The other $10^{6}$ cells were re-suspended in $\mathrm{PBS}$ at $37^{\circ} \mathrm{C}$ for a further $60 \mathrm{~min}$ and assessed by flow cytometry again (18). The intracellular positive rate and fluorescence intensity of ADM were determined using FlowJo v7.6.3 software (FlowJo, LLC, Ashland, OR, USA).

LSC detection. Parental HL-60 and ADM-induced HL-60 cells were co-incubated with PEcy5-CD34 (5 $\mu$ l), ECD-CD38 (5 $\mu \mathrm{l})$ and PE-CD123 (10 $\mu \mathrm{l})$ in $100 \mu \mathrm{l}$ binding buffer and/or fluorescein isothiocyanate, FITC-BCRP $(1 \mu \mathrm{l})$ antibodies, with PEcy5-, ECD-, PE- and FITC-murine IgG1 (with the same corresponding volume as aforesaid) as isotype controls, respectively. The relative proportions of $\mathrm{LSCs}, \mathrm{CD} 34^{+} \mathrm{CD} 38^{-} \mathrm{CD} 123^{+}$ and $\mathrm{BCRP}^{+} \mathrm{CD} 34^{+} \mathrm{CD} 38^{-} \mathrm{CD} 123^{+}$subsets in the cell population were determined by flow cytometry, as aforementioned.

Colony-formation assay. A total of $10^{3}$ cells/ml were seeded in half-solid RPMI 1640 media with 20\% fetal bovine serum and $0.9 \%$ methylcellulose. Following 5- and 10-day incubation at $37^{\circ} \mathrm{C}$ in $5 \% \mathrm{CO}_{2}$, the total number of colonies, defined as a mass of $>40$ cells, within each well was counted under a light microscope (original magnification, $\mathrm{x} 100$ ). Colony-formation rate $=$ total number of colonies $/ 1,000 /$ well $\times 100 \%$ ); three representative fields were imaged.

Statistical analysis. Data were analyzed using SPSS version 17.0 (SPSS, Inc., Chicago, IL, USA). Data are presented as the mean \pm standard deviation. Multiple comparisons between the three groups was performed using two-way analysis of 
A

a

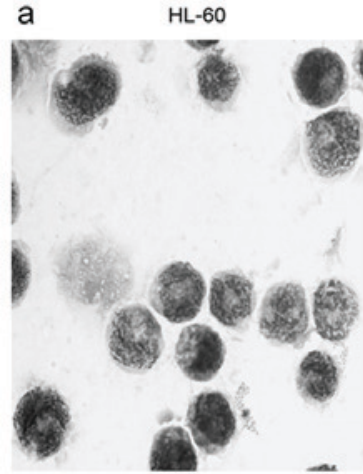

c

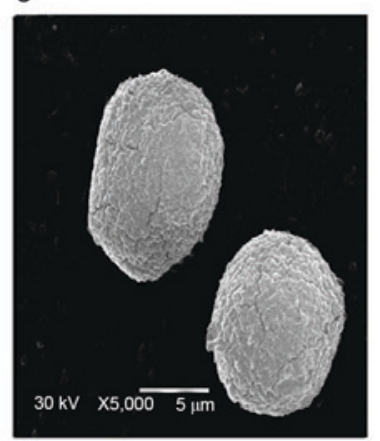

e

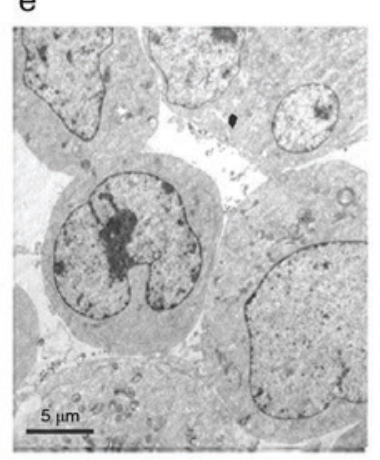

B

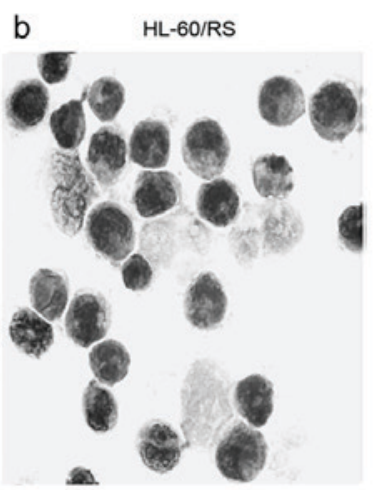

d

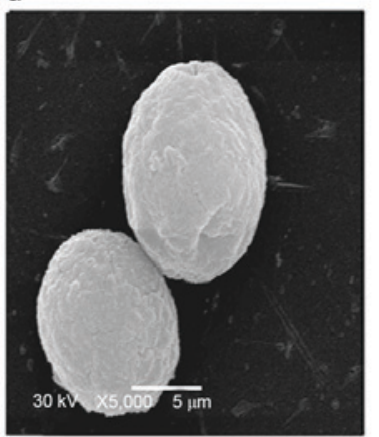

f

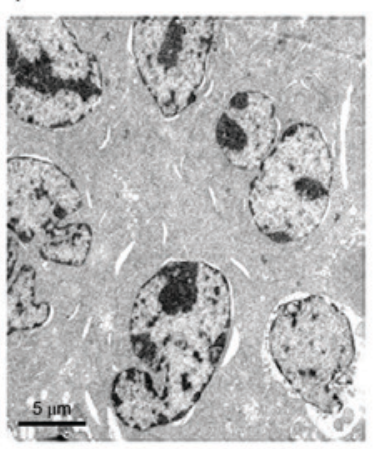

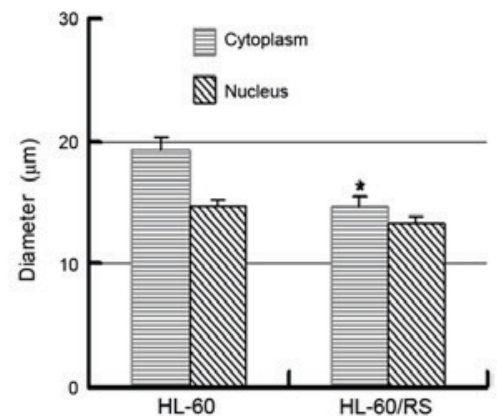

C
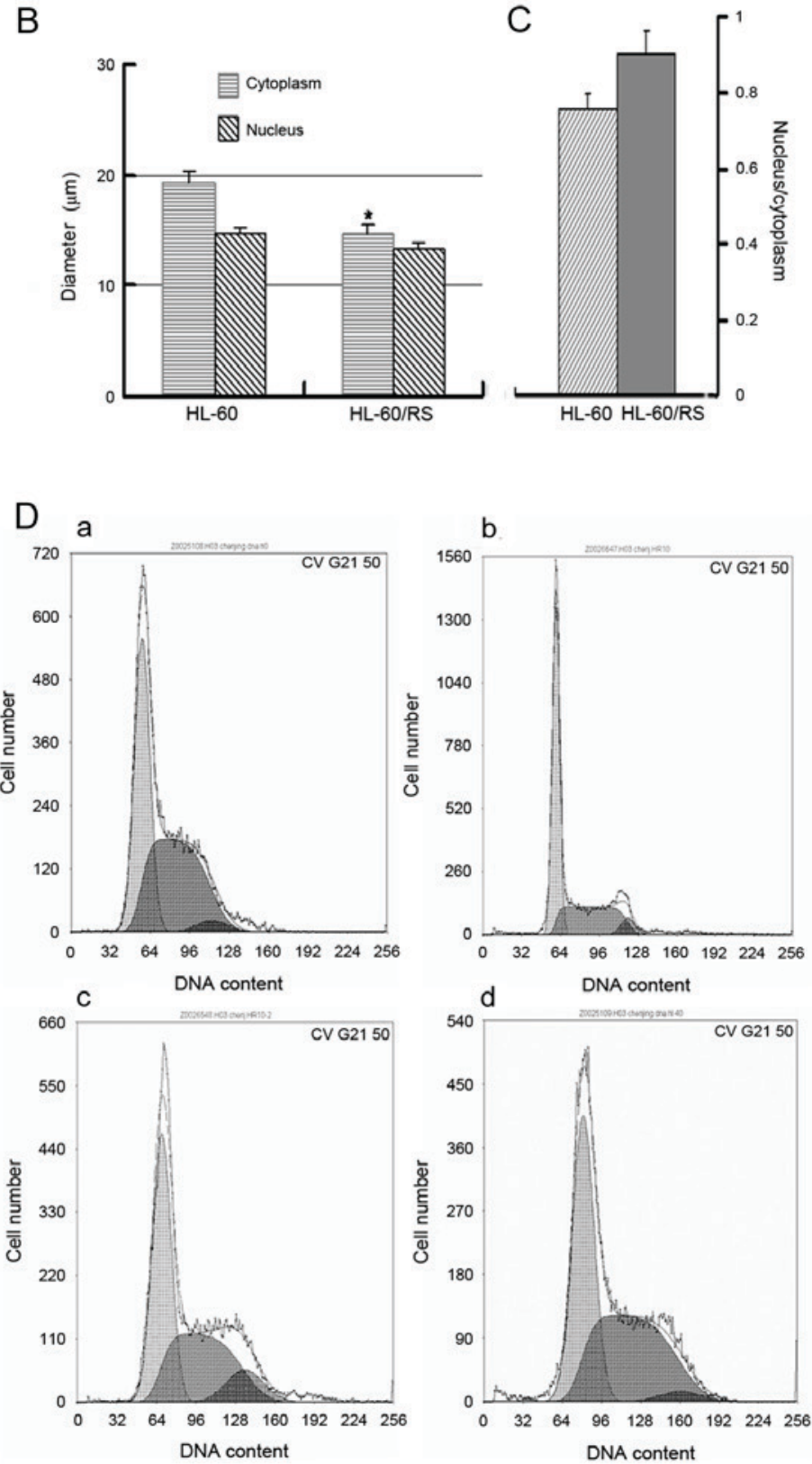

Figure 2. Morphological and cycles change in drug-resistant HL-60/RS cells. (A) Morphological and cycles change in drug-resistant HL-60/RS cells. (A) Morphological changes were examined by light microscopy in (a) sensitive HL-60 cells and (b) HL-60/RS cells stained with Wright-Giemsa stain (original magnification, x1,000). The surface micro-structures of (c) HL-60 cells and (d) HL-60/RS cells were observed by scanning electron microscopy (original magnification, x5,000). The cellular ultrastructures in (e) HL-60 cells and (f) HL-60/RS cells were determined by transmission electron microscopy (original magnification, x5,000). (B) Diameter of the cytoplasm and nucleus in resistant HL-60/RS and parental HL-60 cells. (C) Mean nuclear-cytoplasmic ratios of HL-60/RS and parental HL-60 cells. (D) Cell-cycle distribution of (a) HL-60 and HL-60/RS cells cultured in doxorubicin-free medium for (b) 7, (c) 15 and (d) 60 days, respectively. ${ }^{*} \mathrm{P}<0.05$ compared with HL-60 cells.

variance followed by a Newman-Keuls post hoc test. The intragroup comparisons were performed using paired Student's t-test. All experiments were repeated at least three times. Error bars represent the standard error of the mean and $\mathrm{P}<0.05$ was considered to indicate a statistically significant difference.

\section{Results}

Establishment of multidrug-resistant HL-60 cells. Human promyelocytic leukemia HL-60 cells were selected for the MDR phenotype by stepwise increments of ADM treatment until the cells were able to survive and proliferate normally at a concentration of $40 \mathrm{mg} / \mathrm{l} \mathrm{ADM}$. The resulting cells were 85.68-fold more resistant to ADM compared with the parental HL- 60 cells, as revealed by the $\mathrm{IC}_{50}(\mathrm{mg} / \mathrm{l})$ presented in Fig. $1 \mathrm{~A}$. Additionally, drug-resistance was maintained following culture in the absence of ADM for 3 months or refrigeration for 6 months. These results demonstrated that following a long induction period imitating clinical chemotherapy, HL-60 cells acquired a stable drug-resistant phenotype, and therefore a stable MDR leukemia subline was established.

Resistance and cross-resistance of ADM-selected HL-60 cells. The sensitivity of ADM-induced HL-60 cells to 
chemotherapeutic agents including ADM was analyzed during and at terminal induction. HL-60 cells became increasingly resistant to ADM at increasing concentrations of ADM and increasing exposure times (Fig. 1A). Additionally, ADM-resistant HL-60 cells were also cross-resistant to other chemotherapeutics including cisplatin, daunorubicin, cytarabine, vincristine, arsenic trioxide and etoposide, but not 5-fluorouracil (Fig. 1B). These results confirmed that HL-60/RS cells possessed high resistance to ADM and other numerous chemotherapeutics.

Sensitivity of ADM-selected HL-60 cells to arsenic trioxide. A previous study revealed that the majority of MDR leukemia cells did not develop cross-resistance, but conversely demonstrated higher sensitivity to $\mathrm{As}_{2} \mathrm{O}_{3}$ (4). However, the established HL-60/RS sub-line was strongly cross-resistant to $\mathrm{As}_{2} \mathrm{O}_{3}$, with a 12.89-fold increase in resistance compared with HL-60 cells. Therefore, HL-60/RS cells acquired the unique feature of high $\mathrm{As}_{2} \mathrm{O}_{3}$-resistance (Fig. 1C).

Morphology and cell cycle distribution of HL-60/RS cells. Drug-resistant HL-60/RS and parental sensitive HL-60 cells were similar in size and had similar morphological phenotypes. The nuclei in HL-60/RS cells were uniformly round or oval (Fig. 2A) and exhibited an increased relative nucleus/cytoplasmic ratio compared with the parental cells (Fig. 2B and C). Sensitive HL-60 cells included more mature, band or polymorphonuclear (segmented)-like cells compared with HL-60/RS cells, indicating that HL-60/RS cells were less mature compared with the parental HL-60 cells. Although both cell lines appeared round, HL-60/RS cells had a smooth surface, whereas the surface of parental HL-60 cells appeared rough and more bulging under scanning electron microscopy (Fig. 2A). Electron microscopy revealed morphologic ultrastructural changes in HL-60/RS cells, including denser cytoplasm and nuclear chromatin and increased heterochromatin, compared with untreated, parental cells (Fig. 2A).

The cell cycle distribution was analyzed in HL-60/RS cells, which were exposed to $40 \mathrm{mg} / \mathrm{l} \mathrm{ADM}$ and subsequently cultured continuously in ADM-free conditions. At the early stage (7 days), the distribution of total DNA content in $\mathrm{G}_{0} / \mathrm{G}_{1}$ was markedly higher compared with the parental HL-60 cells, but lower in $\mathrm{S}$ and $\mathrm{G}_{2} / \mathrm{M}$ phases. The cell cycle distribution became similar in both cell types with increasing incubation times (for 15-60 days) and cell proliferation (Fig. 2D).

Expression of drug transporter genes in ADM-selected resistant $H L-60$ cells. In cells tolerant to the highest induced dose of $40 \mathrm{mg} / \mathrm{l} \mathrm{ADM}$, relative $A B C B 1, A B C C 1$ and $A B C G 2$ mRNA expression levels reached 92.5, 45.4 and 75.0-fold of that in sensitive HL-60 cells (Fig. 3B), respectively. The expression of P-gp and BCRP proteins increased simultaneously with increased tolerance to ADM, as determined by flow cytometry. The percentage of $\mathrm{P}-\mathrm{gp}^{+}$cells reached $\sim 100 \%$ in cells tolerant to $5 \mathrm{mg} / \mathrm{l}$ ADM (Fig. 3A). RT-qPCR demonstrated marked increases in $A B C B 1, A B C C 1$ and $A B C G 2$ mRNA expression with increasing tolerance to ADM and extended induction times (Fig. 3Ba). The levels of P-gp, MRP1 and BCRP expression in sensitive parental HL-60 cells and cells tolerant to 30 and $40 \mathrm{mg} / \mathrm{l} \mathrm{ADM}$ cells (HL-60/RS) was analyzed by western
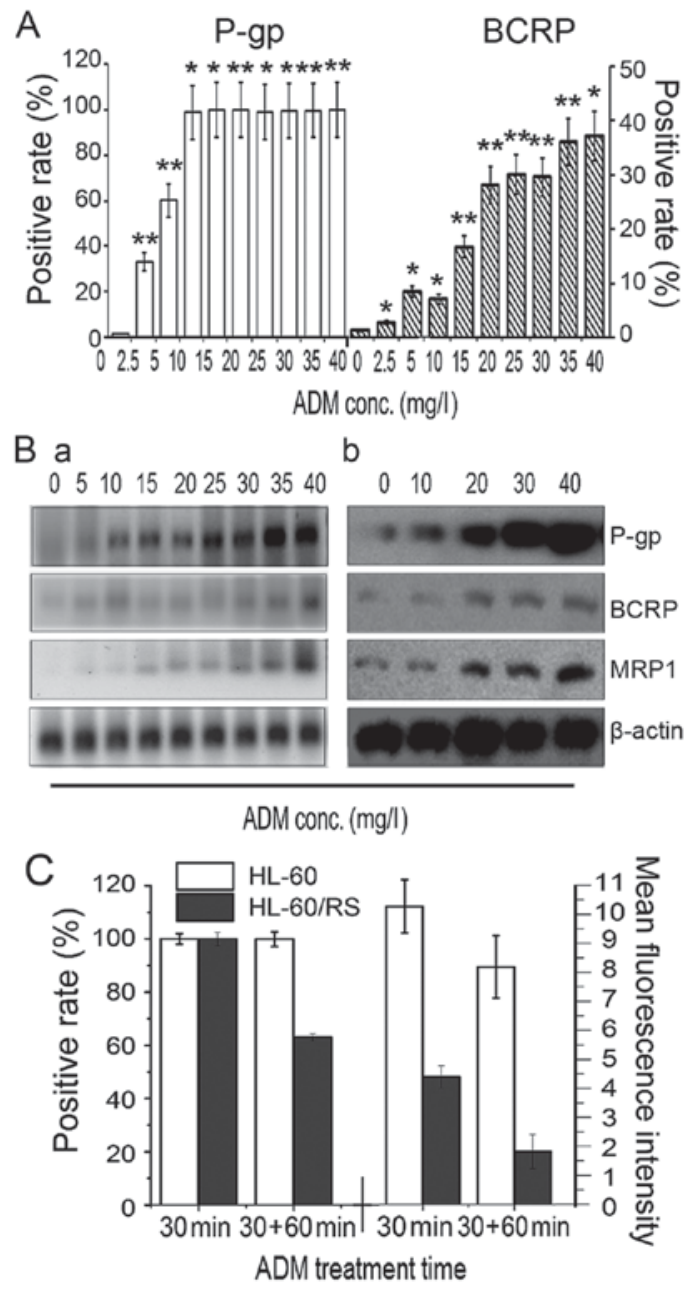

Figure 3. Membrane transporter expression and ADM accumulation-efflux function. (A) The number of $\mathrm{P}_{-} \mathrm{gp}^{+}$and $\mathrm{BCRP}^{+}$cells increased gradually in ADM-induced HL-60 cells with stepwise increases in ADM doses. (B) Levels of $P-g p, M R P 1$ and $B C R P$ (a) gene mRNA expression were determined by reverse transcription-quantitative polymerase chain reaction, and (b) levels of proteins expression were evaluated by western blotting, in HL-60 parental cells (ADM, $0 \mathrm{mg} / \mathrm{l}$ ) and in cells tolerant to various doses of ADM. (C) Accumulation and efflux of HL-60 cells and HL-60/RS cells. The cells were incubated in $30 \mathrm{mg} / 1 \mathrm{ADM}$ medium at $37^{\circ} \mathrm{C}$ for $30 \mathrm{~min}$ and $\mathrm{ADM}$ content was assessed by the number of fluorescence-positive cells and mean fluorescence intensity. Subsequently, the cells were further incubated for $60 \mathrm{~min}$ and re-assessed. ${ }^{*} \mathrm{P}<0.05,{ }^{* *} \mathrm{P}<0.01$ compared with HL-60 cells. ADM, doxorubicin; conc., concentration; P-gp, P-glycoprotein; BCRP, breast-cancer-resistance protein.

blotting, and the findings were consistent with the gene expression results (Fig. 3Bb). These results revealed that long-term and intermittent ADM exposure of HL-60 cells resulted in overexpression of the drug transporters P-gp, MRP and BCRP, which may represent the major mechanism of drug-resistance in HL-60 cells.

Function of drug transporters in ADM-selected resistant $H L-60$ cells. ADM has spontaneous fluorescence that can be used to analyze intercellular residual ADM (18). HL-60 cells and HL-60/RS cells were exposed to $30 \mathrm{mg} / \mathrm{l} \mathrm{ADM}$-containing medium for $30 \mathrm{~min}$. Almost all cells of both lines demonstrated ADM fluorescence. However, the cellular ADM fluorescence intensity in HL-60/RS cells was only $42.75 \%$ of the value of sensitive HL-60 cells. Following re-incubation in ADM-free 
A

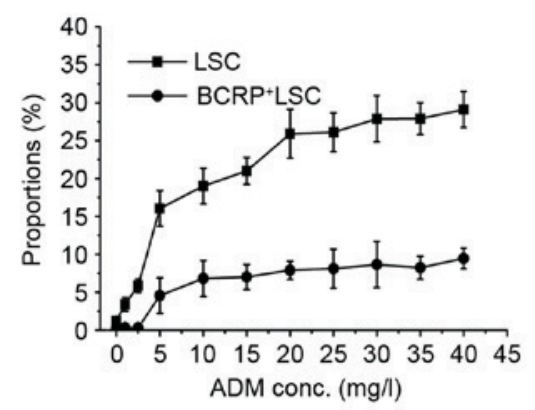

C

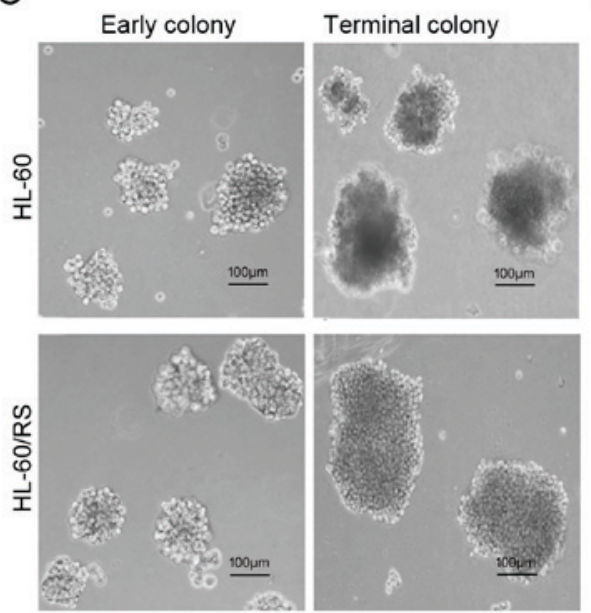

B

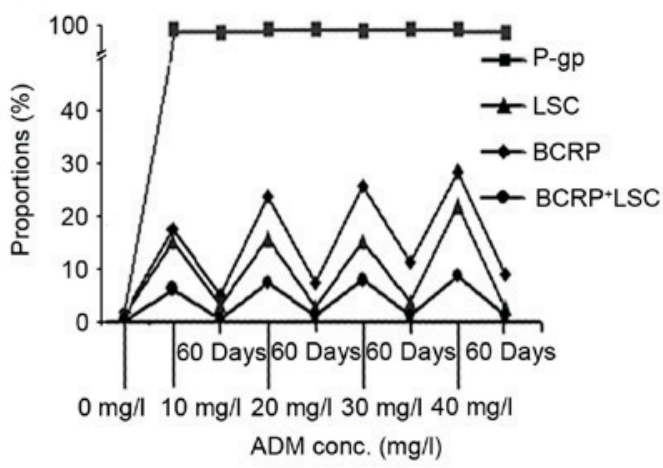

D

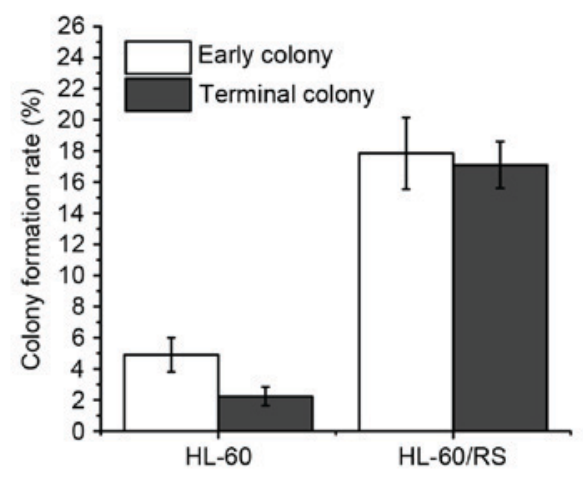

Figure 4. Alterations in subsets of LSCs. (A) Proportions of LSC $\left(\mathrm{CD} 34^{+} \mathrm{CD} 38^{-} \mathrm{CD} 123^{+}\right)$and BCRP ${ }^{+} \mathrm{LSC}$ cells changed synchronously in HL-60 cells tolerant to $0-40 \mathrm{mg} / \mathrm{l} \mathrm{ADM}$ as determined by flow cytometry. (B) HL-60 cells were harvested following selection with 10-40 mg/l ADM as they commenced normal proliferation and were then cultured in ADM-free condition for 60 days. Relative proportions of LSC, BCRP+LSC, P-gp- and BCRP-positive cells were determined by flow cytometry. (C) Early colonies (5 days) and terminal colonies (10 days) of HL-60 and HL-60/RS cells were examined by light microscopy (original magnification, x10). (D) Colony-forming capacities of HL-60 and HL-60/RS cells. LSC, leukemia stem cells; CD, cluster of differentiation; BCRP, breast-cancer-resistance protein; ADM, doxorubicin; P-gp, P-glycoprotein.

medium for a further $60 \mathrm{~min}$, only $62.02 \%$ of HL-60/RS cells retained ADM fluorescence, compared with $\sim 100 \%$ of the HL-60 cells, and the mean fluorescence intensity in HL-60/RS cells remained only $21.01 \%$ of that in HL-60 cells (Fig. 3C).

Dynamic changes in LSC proportion during drug-resistance induction of HL-60 cells. Dynamic changes were observed in the proportions of LSCs and BCRP+LSCs in ADM-selected HL-60 cells during the enhancement of drug-resistance, with $\mathrm{CD} 34^{+} \mathrm{CD} 38^{-} \mathrm{CD} 123^{+}$and $\mathrm{BCRP}^{+} \mathrm{CD} 34^{+} \mathrm{CD} 38^{-} \mathrm{CD} 123^{+}$ phenotypes, respectively. The relative proportion of LSCs in the HL-60 cell population increased notably along with increments of ADM-inducing concentrations and length of induction time. The proportion of $\mathrm{BCRP}^{+} \mathrm{LSC}$ increased synchronously (Fig. 4A). In HL-60 cells tolerant to $40 \mathrm{mg} / \mathrm{l}$ ADM, the proportions of LSCs and BCRP ${ }^{+}$LSCs were 24.25 and 23.63-fold higher compared with the sensitive parental HL-60 cells, respectively (Fig. 4B). These levels gradually fell during culture in ADM-free medium, except for P-gp, which remained stable near 100\% (Fig. 4B). These findings suggested that LSCs have a pivotal role in the acquisition of drug-resistance in leukemia, and $\mathrm{BCRP}^{+}$or $\mathrm{P}_{-} \mathrm{gp}^{+} \mathrm{BCRP}^{+}$cells may be a specific hallmark of the multidrug-resistant LSC subpopulation.
Colony-forming capacity. The self-renewal and unrestricted-proliferation potentials of the cells were analyzed by using the methylcellulose half-solid-medium colony-forming-culture (CFC) method. The early and terminal colony-formation ratios of HL-60/RS cells were 3.64 and 7.67-fold than that of HL-60 cells, respectively. The early colonies were morphologically small and loose but became bigger and denser. Additionally, the majority of the late HL-60 colonies were composed of dead and disintegrating cells (Fig. 4C). The colony formation rate in early and late colonies were markedly higher in tolerant HL-60/RS cells compared with the parental HL-60 cells (Fig. 4D).

\section{Discussion}

MDR is currently a major and unresolved impediment to leukemia therapy $(1-3,10)$. Although numerous extensive studies have investigated leukemia drug-resistance, regulatory pathways andintervention measures, theunderlyingmechanisms remain to be fully understood and few effective or clinically practical countermeasures have been identified (23-25). The fundamental role of LSCs in leukemia-MDR has recently attracted widespread attention. LSCs have been suggested to be a core factor underlying leukemia drug resistance and 
also the key cause of conventional chemotherapy failure and relapse in leukemia $(12,26,27)$. Further studies investigating the characteristics of drug resistance in leukemia and its cellular and molecular mechanisms are required. In the present study, HL-60 human promyelocytic leukemia cells were selected for ADM-resistance by imitating the clinical chemotherapy process. Long-term, intermittent and continuous stepwise increments of ADM concentrations were used to establish a stable MDR leukemia subline (HL-60/RS). The expression of drug-resistance-related genes/proteins and their functions as wells as the LSC composition of the cell lines were examined in relation to the degree of $\mathrm{ADM}$ resistance. Following 22 months of ADM induction, the resistance of HL-60/RS cells to ADM had increased 85.68-fold compared with parental HL-60 cells. These ADM-resistant cells were also cross-resistant to other chemically and functionally unrelated chemotherapeutics. In particular, the ADM-induced cells achieved high $\mathrm{As}_{2} \mathrm{O}_{3}$-resistance. Additionally, the present study demonstrated that the rate of proliferation, cell morphology and cell cycle distribution all differed between HL-60/RS and parental HL-60 cells.

$\mathrm{As}_{2} \mathrm{O}_{3}$ is widely used in chemotherapy for most types of leukemia and solid tumors. $\mathrm{As}_{2} \mathrm{O}_{3}$ has good curative effects and little cross-resistance with conventional chemotherapeutics (2,17-21). Previous studies have revealed that conventional MDR leukemia cells exhibit increased sensitivity to $\mathrm{As}_{2} \mathrm{O}_{3}$ instead of manifesting cross-resistance. This is possibly because $\mathrm{As}_{2} \mathrm{O}_{3}$ is not a P-gp substrate and may even inhibit P-gp expression and activity $(2-4,27)$. However, unlike other ADM-selected P-gp-overexpressing MDR tumor cells, including K562/ADM cells $(2,3,27)$, the HL-60/RS cells established in the present study demonstrated cross-resistance to $\mathrm{As}_{2} \mathrm{O}_{3}$, which is a unique feature in MDR cells.

The reason for strong resistance of HL-60/RS cells to arsenic remains unclear, and the possible mechanisms are still being investigated. It was previously reported that the presence of mutations in the arsenic binding domain of promyelocytic leukemia/retinoic acid receptor $\alpha$ (PML-RARA) induced arsenic resistance in patients treated with $\mathrm{As}_{2} \mathrm{O}_{3}(23-25,28)$. Previous studies in anti-arsenic organisms indicated that overexpression of arsenic-related transporters and glutathione-S-transferases, which mainly exported arsenic leading to intracellular arsenic load reduction, were responsible for the formation of resistance to arsenic (29-31). Follow-up studies are currently proceeding in the laboratory of the authors to investigate the underlying mechanisms of how MDR cells become sensitive or resistant to $\mathrm{As}_{2} \mathrm{O}_{3}$. The preliminary results confirmed that resistance to arsenic in MDR cells was associated with factors, including the overexpression of arsenic transporters.

There is growing evidence demonstrating that LSCs are a main source of leukemia relapse and treatment resistance $(13,26,27,32,33)$. LSCs are naturally resistant to cytotoxic drugs, which kill more mature leukemia cells in the cell proliferation phase, due to their quiescence/dormancy, strong self-DNA-damage-repair capability and overexpression of ABC transporters in LSCs. Therefore, an investigation of the key regulatory pathways of functional $\mathrm{ABC}$ family members in drug-resistance of LSCs is required. In the present study, during the process of ADM induction and colony-forming ability, the proportion of LSCs increased with increasing drug-resistance in HL-60 cells. The proportion of LSCs in HL-60 cells gradually decreased when ADM-induced resistant HL-60 cells were cultured in ADM-free medium, stabilizing at $10 \%$, which was $\sim 10$-fold higher compared with the parental HL-60 cells. Notably, $\sim 100 \%$ of LSCs expressed P-gp. However, only $\sim 30 \%$ expressed BCRP $\left(\mathrm{BCRP}^{+} \mathrm{LSCs}\right)$, which increased (when incubated in ADM-free media for 7 days) or decreased (when incubated in ADM-free media for 15-60 days), but more slowly compared with the total number of LSCs, with increasing resistance to ADM. BCRP in LSCs or leukemic $\mathrm{CD} 34^{+} \mathrm{CD} 38{ }^{-}$stem cells were preferentially expressed and may contribute to their resistant phenotype $(26,28,32)$. Therefore, it was hypothesized that $\mathrm{BCRP}^{+}$or $\mathrm{P}-\mathrm{gp}^{+} \mathrm{BCRP}^{+} \mathrm{LSCs}$ may represent the multi-resistant LSC subset generated by long exposure to ADM, which survived to produce resistant daughter leukemia cells. Repeated stimulation by cytotoxic drugs may drive LSCs to become multi-resistant and develop specific regulatory pathways, which may in turn be transmitted to daughter cells and maintain a drug-resistant leukemia cell population.

In conclusion, the present study established the leukemia HL-60/RS sub-line with MDR characteristics. These characteristics include overexpression of the main $\mathrm{ABC}$ transporter members (P-gp, MRP1 and BCRP), an increased proportion of LSCs and a phenotype of high $\mathrm{As}_{2} \mathrm{O}_{3}$-resistance, which contrasts with the majority of classical MDR leukemia cells. These findings suggested that the main mechanisms underlying MDR in HL-60/RS cells are mediated by excess LSCs and high expression of ABC transporters. Notably, the leukemia MDR cell line was highly cross-resistant to $\mathrm{As}_{2} \mathrm{O}_{3}$. Furthermore, the $\mathrm{BCRP}^{+}$or $\mathrm{P}-\mathrm{gp}^{+} \mathrm{BCRP}^{+}$phenotype may be a specific hallmark of a highly drug-resistant LSC subpopulation. This leukemia MDR cell line may be a good model for further studies that examine the mechanisms underlying $\mathrm{As}_{2} \mathrm{O}_{3}$-resistance, particularly the cross-resistance of conventional chemotherapeutics with $\mathrm{As}_{2} \mathrm{O}_{3}$, and to investigate strategies to reverse chemotherapy resistance in leukemia.

\section{Acknowledgements}

The authors thank Dr David Cushley of International Science Editing (Shannon, Ireland) for language editing and revision of this paper. The present study was supported by the National Natural Science Foundation of China (grant nos. 81541025 and 81141053), the Fundamental Research Funds for the Central Universities (grant no. lzujbky-2016-174), Science and Technology Planning Project from Chengguan District, Lanzhou, Gansu Province, China (grant no. 2015-3-8) and the Natural Science Fund of Gansu (grant no. 1208RJZA183).

\section{References}

1. Matsumoto T, Jimi S, Hara S, Takamatsu Y, Suzumiya J and Tamura K: Importance of inducible multidrug resistance 1 expression in HL-60 cells resistant to gemtuzumab ozogamicin. Leuk Lymphoma 53: 1399-1405, 2012.

2. Zhang QH, Dou HT, Xu P, Zhuang SC and Liu PS: Tumor recurrence and drug resistance properties of side population cells in high grade ovary cancer. Drug Res 65: 153-157, 2015. 
3. Gao F, Dong W, Yang W, Liu J, Zheng Z and Sun K: Expression of P-gp in acute myeloid leukemia and the reversal function of As2O3 on drug resistance. Oncol Lett 9: 177-182, 2015.

4. Chen J, Wei H, Xie B, Wang B, Cheng J and Cheng J: Endoplasmic reticulum stress contributes to arsenic trioxide-induced apoptosis in drug-sensitive and -resistant leukemia cells. Leuk Res 36 $1526-1535,2012$.

5. de Figueiredo-Pontes LL, Pintão MC, Oliveira LC, Dalmazzo LF, Jácomo RH, Garcia AB, Falcão RP and Rego EM: Determination of P-glycoprotein, MDR-related protein 1, breast cancer resistance protein, and lung-resistance protein expression in leukemic stem cells of acute myeloid leukemia. Cytometry B Clin Cytom 74: 163-168, 2008.

6. Munić V, Kelnerić Z, Mikac L and Eraković Haber V: Differences in assessment of macrolide interaction with human MDR1 (ABCB1, P-gp) using rhodamine-123 efflux, ATPase activity and cellular accumulation assays. Eur J Pharm Sci 41: 86-95, 2010.

7. Nakanishi T and Ross DD: Breast cancer resistance protein (BCRP/ABCG2): Its role in multidrug resistance and regulation of its gene expression. Chin J Cancer 31: 73-99, 2012.

8. Zhang Y, Laterra J and Pomper MG: Hedgehog pathway inhibitor HhAntag691 is a potent inhibitor of ABCG2/BCRP and ABCB1/Pgp. Neoplasia 11: 96-101, 2009.

9. Gutiérrez-González A, Belda-Iniesta C, Bargiela-Iparraguirre J, Dominguez G, García Alfonso P, Perona R and Sanchez-Perez I: Targeting Chk2 improves gastric cancer chemotherapy by impairing DNA damage repair. Apoptosis 18: 347-360, 2013.

10. Ding Q, Gu R, Liang J, Zhang X and Chen Y: PI-103 sensitizes acute myeloid leukemia stem cells to daunorubicin-induced cytotoxicity. Med Oncol 30: 395, 2013.

11. Saito Y, Kitamura H, Hijikata A, Tomizawa-Murasawa M, Tanaka S, Takagi S, Uchida N, Suzuki N, Sone A, Najima Y, et al: Identification of therapeutic targets for quiescent, chemotherapy-resistant human leukemia stem cells. Sci Transl Med 2: $17 \mathrm{ra9}, 2010$.

12. Moore N and Lyle S: Quiescent, slow-cycling stem cell populations in cancer: A review of the evidence and discussion of significance. J Oncol 2011: pii:396076, 2011.

13. Pollyea DA, Gutman JA, Gore L, Smith CA and Jordan CT: Targeting acute myeloid leukemia stem cells: A review and principles for the development of clinical trials. Haematologica 99: 1277-1284, 2014

14. Zhou J and Chng WJ: Identification and targeting leukemia stem cells: The path to the cure for acute myeloid leukemia. World J Stem Cells 6: 473-484, 2014.

15. Crews LA and Jamieson CH: Selective elimination of leukemia stem cells: Hitting a moving target. Cancer Lett 338: 15-22, 2013.

16. Marques DS, Sandrini JZ, Boyle RT, Marins LF and Trindade GS: Relationships between multidrug resistance (MDR) and stem cell markers in human chronic myeloid leukemia cell lines. Leukemia Res 34: 757-762, 2010.

17. Buda G, Orciuolo E, Maggini V, Galimberti S, Barale R, Ross AM and Petrini M: MDR1 modulates apoptosis in CD34 ${ }^{+}$ leukemic cells. Ann Hematol 87: 1017-1018, 2008.

18. Zhao D, Jiang Y, Dong X, Liu Z, Qu B, Zhang Y, Ma N and Han Q: Arsenic trioxide reduces drug resistance to adriamycin in leukemic K562/A02 cells via multiple mechanisms. Biomed Pharmacother 65: 354-358, 2011.

19. Perkins C, Kim CN, Fang G and Bhalla KN: Arsenic induces apoptosis of multidrug-resistant human myeloid leukemia cells that express Bcr-Abl or overexpress MDR, MRP, Bcl-2, or Bcl-x(L). Blood 95: 1014-1022, 2000.
20. Zhao H, Guo W, Peng C, Ji T and Lu X: Arsenic trioxide inhibits the growth of adriamycin resistant osteosarcoma cells through inducing apoptosis. Mol Biol Rep 37: 2509-2515, 2010.

21. Beauchamp EM, Ringer L, Bulut G, Sajwan KP, Hall MD, Lee YC, Peaceman D, Ozdemirli M, Rodriguez O, Macdonald TJ, et al: Arsenic trioxide inhibits human cancer cell growth and tumor development in mice by blocking Hedgehog/GLI pathway. J Clin Invest 121: 148-160, 2011.

22. Wei H, Su H, Bai D, Zhao H, Ge J, Wan B, Yao X and Ma L: Arsenic trioxide inhibits p-glycoprotein expression in multidrug-resistant human leukemia cells that overexpress MDR1 gene. Chin Med J 116: 1644-1648, 2003.

23. Fung TK and So CW: Overcoming treatment resistance in acute promyelocytic leukemia and beyond. Oncotarget 4: 1128-1129, 2013.

24. Tomita A, Kiyoi H and Naoe T: Mechanisms of action and resistance to all-trans retinoic acid (ATRA) and arsenic trioxide $\left(\mathrm{As}_{2} \mathrm{O}_{3}\right)$ in acute promyelocytic leukemia. J Hematol 97: 717-725, 2013.

25. Zhu HH, Qin YZ and Huang XJ: Resistance to arsenic therapy in acute promyelocytic leukemia. N Engl J Med 370: 1864-1866, 2014.

26. Felipe Rico J, Hassane DC and Guzman ML: Acute myelogenous leukemia stem cells: From Bench to Bedside. Cancer Lett 338: 4-9, 2013.

27. Wang F, Wang XK, Shi CJ, Zhang H, Hu YP, Chen YF and Fu LW: Nilotinib enhances the efficacy of conventional chemotherapeutic drugs in $\mathrm{CD} 34^{+} \mathrm{CD} 38$ stem cells and $\mathrm{ABC}$ transporter overexpressing leukemia cells. Molecules 19: 3356-3375, 2014.

28. Lo-Coco F, Avvisati G, Vignetti M, Thiede C, Orlando SM, Iacobelli S, Ferrara F, Fazi P, Cicconi L, Di Bona E, et al: Retinoic acid and arsenic trioxide for acute promyelocytic leukemia. N Engl J Med 369: 111-121, 2013

29. $\mathrm{Xu} \mathrm{S}$, Zhang YF, Carew MW, Hao WH, Loo JF, Naranmandura $\mathrm{H}$ and Le XC: Multidrug resistance protein 1 (ABCC1) confers resistance to arsenic compounds in human myeloid leukemic HL-60 cells. Arch Toxicol 87: 1013-1023, 2013.

30. Hemmingsson O, Nöjd M, Kao G and Naredi P: Increased sensitivity to platinating agents and arsenite in human ovarian cancer by downregulation of ASNA1. Oncol Rep 22: 869-875, 2009.

31. Matulis SM, Morales AA, Yehiayan L, Lee KP, Cai Y and Boise LH: Alterations in glutathione levels and apoptotic regulators are associated with acquisition of arsenic trioxide resistance in multiple myeloma. PLoS One 7: e52662, 2012.

32. Yi J, Chen J, Sun J and Wei HL: The relationship between multi-drug resistance and proportion of leukemia stem cells and expression of drug transporters in drug-resistant leukemia K562/ADM cells. Zhonghua Yi Xue Za Zhi 89: 1741-1744, 2009 (In Chinese).

33. Qiu S, Jia Y, Xing H, Yu T, Yu J, Yu P, Tang K, Tian Z, Wang H, Mi Y, et al: $\mathrm{N}$-Cadherin and Tie-positive CD $34^{+} \mathrm{CD} 38^{-} \mathrm{CD} 123^{+}$ leukemic stem cell populations can develop acute myeloid leukemia more effectively in NOD/SCID mice. Leuk Res 38: 632-637, 2014 